pneumatic principle can be applied also to measure the specific gravity of liquids of variable density by two standpipes connected to a differential pressure indicator or recorder. In a list recently issued, Messrs. Negretti and Zambra, who have wide experience in the manufacture of instruments of these types among many others, have supplemented the illustrations with accessory schedules and diagrams showing how the several models are employed and connected under different conditions of service. More than a catalogue, it is thus a handbook for the reference of those responsible for the selection and installation of level measuring instruments.

\title{
THE PUBLIC HEALTH IN WAR-TIME*
}

$\mathrm{I}^{\mathrm{N}}$ every war of which we have records the wastage from disease has outnumbered many times the losses from killed and wounded. Figures from the War of 1914-18 support this statement, as well as the experience of the Walcheren expedition and the Crimean campaign.

Military and civil authorities are both interested in the maintenance of the public health in war-time. Military and civilian health authorities successfully co-operated in this respect during the War of 1914-18, and similar arrangements have been made in the present war.

While indirect war consequences, such as alterations in diet, excess of work and worry and the pandemic of influenza (1918-19), contributed to increased rates of mortality among civilians in the War of 1914-18, the record of civil public health was good on the whole. The population increased and the infant mortality rate was lowered. It must be remembered that that War saw the beginnings of those personal health services which have done so much to improve the health of the community; for example, the School Medical Service (1907), the Insurance Medical Service (1912), the Tuberculosis, Maternity and Child Welfare and Venereal Disease Services. It is a harder task in the present War to maintain the health services at the high level they have reached. In addition, unprecedented demands have been made on the national health services. The central health authority has become a more important arm of defence, and has had to organize an emergency medical service, in itself a stupendous task, and an evacuation scheme for school children, expectant mothers young children and other priority classes of the population.

An account of the emergency medical service and of the medical problems of the evacuation scheme was also given.

Certain criticisms of the evacuation scheme were discussed. It was emphasized that the Public Health and School Medical Services should not be blamed for departures from the normal standards of cleanliness and conduct found in certain of the evacuees. The root cause of these conditions lies in the home. They mean that slum clearance has not yet gone far enough, that low standards of living still persist, and that the lessons taught in the school and clinic sometimes fail to reach the older generation.

It was suggested that the policy of preparing for casualties and of evacuation may have played no inconsiderable part in the present freedom of Great Britain from enemy air raids.

Reference was made to certain diseases-deficiency diseases, tuberculosis, venereal diseases, influenza, infectious diseases, cerebrospinal fever-which are the objects of special concern in this War. The civilian arm has yet to receive its baptism of fire. If that stern ordeal comes, it will endeavour to keep the flag of national health flying in the storm of war as zealously as it did in the sunshine of peace.

* Substance of a Chadwick Public Lecture delivered on February 20 by Sir Arthur MacNalty, K.C.B., Chief Medical Officer of the Ministry of Health.

\section{HAULAGE PRECAUTIONS IN MINES}

$\mathrm{O}^{\mathrm{F}}$ the deaths caused by haulage accidents in mines, the fact that over a period of eight years nearly 25 per cent were due to runaway tubs is sufficiently serious to indicate this as a subject demanding inquiry. One of the lines of research undertaken in this connexion was to determine the relative degree of effectiveness of the different types of backstay which are used as one means of arresting potential runaways. The backstay, which is known by several local names, is a strong steel bar which trails along the rail track at the rear of the string of tubs, its function being to dig into the track if the train tends to run back. Frequently its action is ineffective, and this led to one line of research being directed by the Department of Mines towards ascertaining the chief causes of the failures and the ways and means of preventing them by improving the design of this simple safeguard. The results of this investigation have now been published under the title "Backstays for use in Mines" (Safety in Mines Research Board Paper No. 103. H.M. Stationery Office. 1s. net), which describes all the steps taken and results obtained and makes available to the coal mining industry the conclusions reached.

Representative types of backstays having been obtained from several coalfields, these were examined for variations in design. They were classified in four groups, the classification mainly depending on the method of attachment to the tub. In other respects very marked differences were noted; length varied from 23 to 42 inches and weight from $9 \frac{3}{4}$ to $72 \mathrm{lb}$. They were subjected to a number of tests under conditions simulating those which might actually 